\title{
Dipeptide $\gamma$-secretase inhibitor treatment enhances the anti-tumor effects of cisplatin against gastric cancer by suppressing cancer stem cell properties
}

\author{
RYO KATO $^{1}$, MASAYA IWAMURO ${ }^{1}$, HIDENORI SHIRAHA ${ }^{1}$, SHIGERU HORIGUCHI ${ }^{1}$, EMI TANAKA ${ }^{2}$, \\ KEN MATSUMOTO ${ }^{2}$, ATSUSHI OHYAMA ${ }^{1}$, HIROAKI SAWAHARA ${ }^{3}$, TERUYA NAGAHARA ${ }^{4}$, \\ DAISUKE UCHIDA ${ }^{1}$, KOICHIRO TSUTSUMI ${ }^{1}$ and HIROYUKI OKADA ${ }^{1}$ \\ ${ }^{1}$ Department of Gastroenterology and Hepatology, Okayama University Graduate School of Medicine, \\ Dentistry and Pharmaceutical Sciences; ${ }^{2}$ Okayama University Medical School, Okayama 700-8558; \\ ${ }^{3}$ Department of Internal Medicine, Akaiwa Medical Association Hospital, Okayama 709-0816; \\ ${ }^{4}$ Department of Gastroenterology and Hepatology, Japanese Red Cross Okayama Hospital, Okayama 700-8607, Japan
}

Received December 22, 2017; Accepted August 2, 2018

DOI: $10.3892 / \mathrm{ol} .2018 .9301$

\begin{abstract}
The $\gamma$-secretase inhibitor blocks Notch activity by preventing its cleavage at the cell surface. In the present study, the effect of the $\gamma$-secretase inhibitor on the viability of gastric cancer cells when administered in combination with cisplatin was investigated, with particular focus on CD44 ${ }^{\text {high }}$ Lgr- $5^{\text {high }}$ cancer cells. The four gastric cancer cell lines, MKN45, MKN74, SC-6-JCK and SH-10-TC, were used for the experiments. In the MTT assay, treatment with $25 \mu \mathrm{M}$ dipeptide $\gamma$-secretase inhibitor (DAPT) alone did not affect cell proliferation in any of the four cell lines. Gastric cancer cells subjected to combination treatment with DAPT and cisplatin exhibited decreased viability when compared with those treated with cisplatin alone. Flow cytometry was performed to evaluate the expression of cluster of differentiation (CD)-44 and leucine-rich repeat-containing G-protein coupled receptor 5 (Lgr-5), two cancer stem cell markers in gastric cancers. Treatment with cisplatin alone significantly increased the proportion of CD $44^{\text {high }} \mathrm{Lgr}-5^{\text {high }}$ cells. However, the addition of DAPT to cisplatin reduced the CD $44^{\text {high }} \mathrm{Lgr}-5^{\text {high }}$ fraction, suggesting that DAPT reduced the number of gastric cancer cells. In conclusion, the present study demonstrated
\end{abstract}

Correspondence to: Dr Masaya Iwamuro, Department of Gastroenterology and Hepatology, Okayama University Graduate School of Medicine, Dentistry and Pharmaceutical Sciences, 2-5-1 Shikata-cho, Kita-ku, Okayama 700-8558, Japan

E-mail: iwamuromasaya@yahoo.co.jp

Abbreviations: CDDP, cisplatin; DAPT, dipeptide $\gamma$-secretase inhibitor; DMSO, dimethyl sulfoxide; NICD, intracellular domain of the Notch receptor

Key words: cancer stem cell, $\gamma$-secretase inhibitor, gastric cancer, Notch pathway the synergistic effects of DAPT in combination with cisplatin by decreasing the survival of gastric cancer cells. In addition, combination treatment with DAPT reduced the number of CD44 ${ }^{\text {high }}$ Lgr- $5^{\text {high }}$ cells, which are thought to exhibit cancer stem cell properties. These results highlight the therapeutic potential of DAPT in gastric cancer treatment.

\section{Introduction}

Gastric cancer remains one of the leading causes of cancer mortality (1). Although new anti-tumor drugs, such as molecular target therapeutic agents, have been developed and used for the treatment of gastric cancers, disease progression often occurs even during chemotherapy. Resistance to chemotherapy is a major obstacle in the therapeutic management of gastric cancer. Several possible mechanisms responsible for chemoresistance have been proposed. First, the cancer stem cell theory hypothesizes that cancer stem cells develop tumorigenic properties and resistance to chemotherapeutic agents over time (2-5). Cancer stem cells possess self-renewal properties and are capable of differentiating into multiple cell types, which in turn promotes clonal tumor initiation and long-term clonal repopulation potential within the tumor. Furthermore, these cancer stem cells can exhibit intrinsic or acquired chemo-resistance, which are mediated by multiple mechanisms, including the formation of tumor spheroids, protection by a vascular niche, residence in the quiescent state, overexpression of transporter proteins associated with drug efflux and detoxification, and activation of antiapoptotic signaling pathways (2). Thus, based on the cancer stem cell concept, the development of new strategies targeting these cells is expected to improve outcomes of gastric cancer patients.

The Notch pathway is involved in various developmental and homeostatic processes, cell proliferation regulation, cell fate, differentiation, and cell death (6). The Notch pathway plays a role in juxtacrine interactions, during which intercellular signals are transmitted to adjacent responding cells. The Notch cascade is mediated by Notch ligands and receptors, as 
well as the intracellular domain of the Notch receptor (NICD). The interactions between Notch ligands and their receptors initiate $\gamma$-secretase-dependent cleavage of the Notch receptor and leads to the release of NICD, which then translocates into the nucleus to regulate gene expression and other effector molecules. Several studies have reported that Notch signaling is associated with various types of cancers $(7,8)$. For example, Notch1 mRNA levels were demonstrated to be upregulated in gastric cancer tissues. Moreover, Notch2 receptor, Notch ligands, Jagged-1, Jagged-2, DLL-1, and DLL-3, and the major downstream targets of Notch signaling, namely, HES-1, and $H E S$-2, were also significantly upregulated in gastric cancer tissues relative to normal gastric tissues (9). Another study reported that HES-1 can suppress the transcription of genes associated with differentiation of gastrointestinal epithelial cells. Thus, the above findings suggested that the canonical Notch signaling pathway contributes to the maintenance of cancer stem cell properties during gastric cancer carcinogenesis $(10,11)$. Conversely, inhibition of the Notch pathway can reduce the cancer stem cell population and eventually lead to improved chemotherapy efficacy.

In the present study, we investigated the effects of $\gamma$-secretase inhibitor, which effectively blocks Notch activity by preventing its cleavage at the cell surface, on the viability of gastric cancer cells when administered in combination with cisplatin. Our experiments focused on CD $44^{\text {high }} \operatorname{Lgr}-5^{\text {high }}$ cancer cells, which represent a cancer stem cell-like population.

\section{Materials and methods}

Cell lines and reagents. The human gastric adenocarcinoma cell lines MKN45 and MKN74 were purchased from the RIKEN BioResource Center (Ibaraki, Japan). Cells were grown in RPMI-1640 medium supplemented with $10 \%$ heat-inactivated fetal bovine serum (FBS), penicillin $(5,000 \mathrm{U} / \mathrm{ml})$, streptomycin $(5 \mathrm{mg} / \mathrm{ml})$ and amphotericin $\mathrm{B}$ $(250 \mu \mathrm{g} / \mathrm{ml})$ at $37^{\circ} \mathrm{C}$ in a balanced air humidified incubator with $5 \% \quad \mathrm{CO}_{2}$ atmosphere. SC-6-JCK and SH-10-TC were procured from Cell Resource Center for Biomedical Research, Cell Bank, Institute of Development, Aging and Cancer, Tohoku University (Sendai, Japan). Cells were grown in RPMI-1640 medium supplemented with $10 \%$ heat-inactivated FBS, penicillin $(5,000 \mathrm{U} / \mathrm{ml})$, streptomycin $(5 \mathrm{mg} / \mathrm{ml})$, and amphotericin $\mathrm{B}(250 \mu \mathrm{g} / \mathrm{ml})$ at $37^{\circ} \mathrm{C}$ in a balanced air humidified incubator with $5 \% \mathrm{CO}_{2}$ atmosphere.

Cisplatin was purchased from Wako (no. 3039-20093; Tokyo, Japan). Dipeptide $\gamma$-secretase inhibitor (DAPT, $\gamma$-secretase inhibitor IX, N-[N-(3,5-difluorophenacetyl)-L-alanyl]sphenylglycine t-butyl ester) was purchased from Merck KGaA (CALBIOCHEM; no. 565770, Darmstadt, Germany) and dissolved in dimethyl sulfoxide (DMSO).

MTT assay. Inhibition of cellular proliferation was measured by the modified MTT [3-(4,5 dimethylthiazol-2-yl)-2, 5-diphenyltetrazolium bromide] assay, which distinguishes live cells based on their ability to convert thiazolyl blue to dark blue formazan. Cells were seeded into 24-well culture plates at a density of approximately 10,000 cells/well. After $24 \mathrm{~h}$, cells were added with $500 \mu \mathrm{l}$ of medium with or without cisplatin and DAPT. MTT assay was performed after $72 \mathrm{~h}$ of incubation. In this experiment, the culture media were not replaced nor added with DAPT and/or cisplatin for $72 \mathrm{~h}$. After treatment, each well was added with $50 \mu \mathrm{l}$ of MTT and incubated at $37^{\circ} \mathrm{C}$ for $1 \mathrm{~h}$. Subsequently, wells were added with $400 \mu \mathrm{l}$ of DMSO for $30 \mathrm{~min}$ at room temperature to solubilize the formazan product. The absorbance at $570 \mathrm{~nm}$ was measured using MULTISKAN GO (Thermo Fisher Scientific, Inc., Waltham, MA, USA).

Western blotanalysis. Approximately 200,000 cells were seeded into each well of six-well culture plates. After $24 \mathrm{~h}$, cells were treated with $2 \mathrm{ml}$ of medium/well and $16 \mu \mathrm{l}$ of DMSO (control) or $50 \mu \mathrm{M}$ DAPT. Cells were harvested after 24,48 , and $72 \mathrm{~h}$ and analyzed via western blot analysis. Antibodies targeting NICD (no. AP21093a; Abgent, Inc., San Diego, CA, USA), $\beta$-actin (no. 4967; Cell Signaling Technology, Inc., Danvers, MA, USA), and HES-1 (no. ab49170; Abcam, Cambridge, UK) were used as primary antibodies. HRP-conjugated anti-rabbit IgG antibody (no. 7074; Cell Signaling Technology, Inc.) was used as secondary antibody.

Next, we investigated protein expression in the presence of DAPT and/or cisplatin. Approximately 200,000 cells were seeded into each well of six-well culture plates. After $24 \mathrm{~h}$ of incubation, cells were treated with $2 \mathrm{ml}$ of medium/well with or without cisplatin and DAPT for $72 \mathrm{~h}$. Antibodies targeting NICD, $\beta$-actin, and HES- 1 were used as primary antibodies. HRP-conjugated anti-rabbit IgG antibody was used as secondary antibody, as described above.

Flow cytometry assay. Approximately $1.0 \times 10^{6}$ cells were seeded into a $100-\mathrm{mm}$ plate and cultured in $10 \mathrm{ml}$ of medium with or without cisplatin and DAPT for $72 \mathrm{~h}$. Cells were assessed using a MACS Quant Analyzer (Miltenyi Biotec, Bergisch Gladbach, Germany). Fluorescein isothiocyanate-conjugated anti-CD44 (no. 130-095-195; Miltenyi Biotec) and allophycocyanin-conjugated anti-Lgr-5 antibodies (no. 130-100-854; Miltenyi Biotec) were used as markers for gastric cancer stem cells. The voltage settings were adjusted in histograms of the control samples that were treated with DMSO alone and the visual peak of the population was set as $10^{\circ}$. We used $10^{\circ}$ as the threshold point. For example, for CD44 expression analysis, cells with fluorophore brightness above $10^{\circ}$ were judged as CD $44^{\text {high }}$, and those below $10^{\circ}$ were judged as CD44 $4^{\text {low }}$.

To calculate statistical differences with respect to percentages of CD $44^{\text {high }}$ or $\mathrm{Lgr}-5^{\text {high }}$ cells between samples, approximately $5.0 \times 10^{5}$ cells were seeded into 6 -well plates and cultured in $2 \mathrm{ml} /$ well of medium with or without cisplatin and DAPT. Three wells were used for each condition. After $72 \mathrm{~h}$, cells were labeled with anti-CD44 and anti-Lgr-5 antibodies and assessed using a MACS Quant Analyzer.

Statistical analysis. Data are presented as the mean \pm standard deviation of three independent experiments. Statistical analyses were performed using JMP 14.0.0 software (SAS Institute, Inc., Cary, NC, USA), and one-way analysis of variance followed by a Tukey-Kramer post hoc test for multiple comparisons. $\mathrm{P}<0.05$ was considered to indicate a statistically significant difference. 


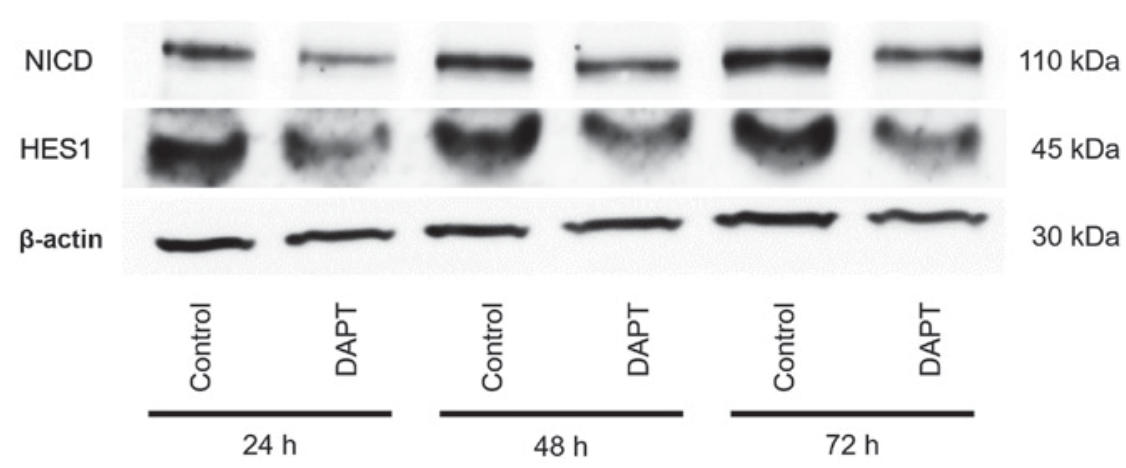

Figure 1. Expression of NICD and the downstream protein HES1 in MKN45 cells. MKN45 cells were treated with $50 \mu \mathrm{M}$ DAPT for 24, 48 and $72 \mathrm{~h}$. Then, cells were lysed and evaluated via western blot analysis using antibodies targeting NICD and HES1. Antibodies against $\beta$-actin were used to verify the equal loading of cellular proteins. Representative blots of $>3$ independent experiments are presented. NICD, intracellular domain of the Notch receptor; HES1, Hes family basic helix-loop-helix transcription factor 1; DAPT, dipeptide $\gamma$-secretase inhibitor.

\section{Results}

Seventy-two-hour exposure to DAPT suppresses downstream targets of Notch signaling. Results of western blot analysis revealed that NICD and HES-1, the primary downstream targets of Notch signaling, were downregulated for at least $72 \mathrm{~h}$ in MKN45 cells (Fig. 1). Therefore, cells were analyzed after $72 \mathrm{~h}$ of exposure to the reagents in the subsequent analyses.

Exposure to $0.5 \mu \mathrm{g} / \mathrm{ml}$ cisplatin reduces gastric cancer cell number. We determined the cisplatin concentration that reduced the number of gastric cancer cells by 20 to $30 \%$. In MKN45 cells, the results of MTT assay showed that treatment with $0.1,0.5$, and $1.0 \mu \mathrm{g} / \mathrm{ml}$ cisplatin resulted in 7.0, 20.0 and $37.8 \%$ reduction in the number of gastric cancer cells relative to control samples, respectively (Fig. 2A). Similarly, in MKN 74 cells, $0.1,0.5$ and $1.0 \mu \mathrm{g} / \mathrm{ml}$ cisplatin resulted in 12.2 , 25.1 and $41.9 \%$ reduction in the number of gastric cancer cells, respectively (Fig. 2B). Therefore, $0.5 \mu \mathrm{g} / \mathrm{ml}$ cisplatin was used in subsequent experiments.

Combined treatment with cisplatin and DAPT downregulates both Notch and HES-1. We investigated the effect of DAPT in combination with $0.5 \mu \mathrm{g} / \mathrm{ml}$ cisplatin. Results of western blot analysis showed that treatment with cisplatin alone did not affect NICD or HES-1 in both MKN45 and MKN74 cells (Fig. 3). In MKN74 cells, a higher concentration of $25 \mu \mathrm{M}$ DAPT did not produce evident changes in NICD and HES-1 levels, whereas $50 \mu \mathrm{M}$ DAPT downregulated both Notch and HES-1 (Fig. 3B). In MKN45 cells, treatment with 25 or $50 \mu \mathrm{M}$ DAPT alone slightly reduced the protein levels of NICD and HES-1, but downregulation was more evident after combined treatment with cisplatin and 25 or $50 \mu \mathrm{M}$ DAPT (Fig. 3A).

Combined treatment with cisplatin and DAPT synergistically suppresses gastric cancer cell proliferation. MTT assay was performed to investigate cell proliferation in four gastric cancer cell lines, namely, MKN45, MKN74, SC-6-JCK, and SH-10-TC, in the presence of DAPT and/or cisplatin. Results showed that treatment with $25 \mu \mathrm{M}$ DAPT alone did not affect cell proliferation in all four cell lines (Fig. 4). Combined treatment with DAPT and cisplatin decreased the number of gastric cancer cells than treatment with cisplatin alone. The difference reached statistical significance when the cells were treated with $50 \mu \mathrm{M}$ DAPT and cisplatin in all four cell lines. The dose-dependent inhibitory effect of DAPT on cell proliferation when administered in combination with cisplatin was most apparent in the SC-6-JCK cell line, in which the number of gastric cancer cells was reduced by $30.2 \%$ upon treatment with $25 \mu \mathrm{M}$ DAPT and by $58.7 \%$ upon treatment with $50 \mu \mathrm{M}$ DAPT relative to samples treated with cisplatin alone.

DAPT and cisplatin combination treatment reduces expression of stem cell markers CD44 and Lgr-5 more than cisplatin treatment alone. Fig. 5 shows the results of flow cytometry analysis. As described above, CD44 and Lgr-5 were used as cancer stem cell markers for gastric cancer. In untreated MKN45 cells, $18.2 \%$ of cells were positive for both CD44 and Lgr-5 (Fig. 5A, left above). Although treatment with cisplatin alone increased the number of cells positive for CD44 and Lgr-5 to $41.8 \%$ (Fig. 5A, right above), addition of DAPT to cisplatin significantly reduced the number of cells to $34.7 \%$ (Fig. 5A, right below). Similarly, in MKN74 cells, cisplatin treatment increased the number of cells positive for CD44 and Lgr-5 from 15.9 to $34.8 \%$ (Fig. 5B). Combined treatment with DAPT and cisplatin decreased the number of CD44-and Lgr-5-positive cells to 21.7\%.

Treatment with cisplatin alone increased the proportion of $\mathrm{CD} 44^{\text {high }} \mathrm{Lgr}-5^{\text {high }}$ cells, whereas combination treatment with cisplatin and DAPT reduced the CD $44^{\text {high }} \mathrm{Lgr}-5^{\text {high }}$ fraction. However, although DAPT treatment decreased the proportion of CD44 $4^{\text {high }}$ cells, its effects on $\mathrm{Lgr}-5^{\text {high }}$ cells were not consistent. For instance, in MKN74 cells, combination treatment with DAPT and cisplatin (35.8\%) reduced the number of $\mathrm{Lgr}-5^{\text {high }}$ cells $\left(\mathrm{CD} 44^{\text {high }} \mathrm{Lgr}-5^{\text {high }}\right.$ cells plus $\mathrm{CD} 44^{\text {low }} \mathrm{Lgr}-5^{\text {high }}$ cells) compared to treatment with cisplatin alone (46.8\%). The decrease in the number of Lgr- $5^{\text {high }}$ cells upon combination treatment with DAPT and cisplatin compared with that observed with cisplatin alone was more apparent in SC-6-JCK cells (84.6 to $68.8 \%)$. On the other hand, the DAPT treatment group showed a similar proportion of $\mathrm{Lgr}-5^{\text {high }}$ cells (32.7\%) as that of the control (no treatment) group (31.0\%). Moreover, in MKN45 cells, the DAPT treatment group showed a higher number of $\mathrm{Lgr}-5^{\text {high }}$ cells $(40.4 \%)$ than that of the control group (33.7\%). The proportion of Lgr- $5^{\text {high }}$ cells observed after combination treatment with DAPT and cisplatin (59.1\%) was similar to that observed after cisplatin treatment (54.0\%). 

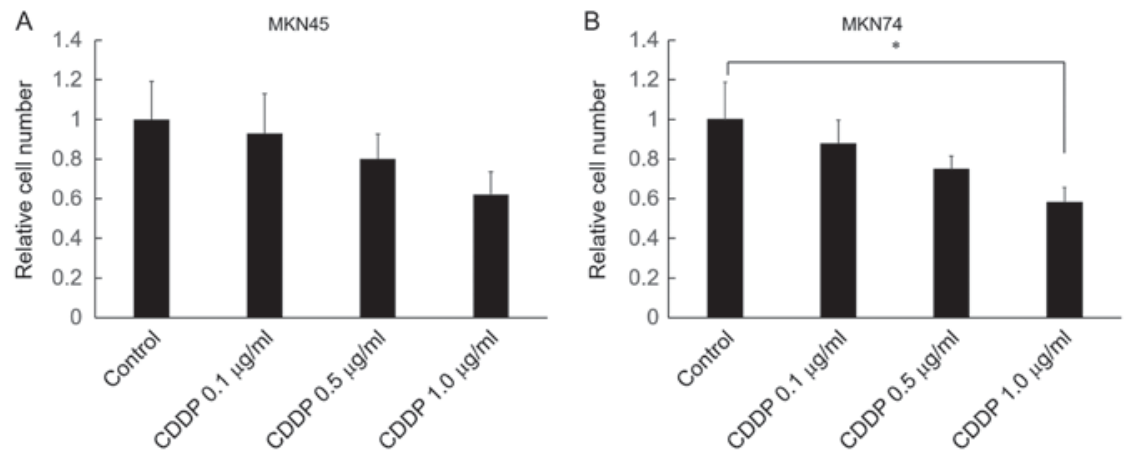

Figure 2. Effect of CDDP in (A) MKN45 and (B) MKN74 cells. Cells were treated with $0.1,0.5$ or $1.0 \mu \mathrm{g} / \mathrm{m}$ cisplatin for $72 \mathrm{~h}$. Then, cells were lysed and cell proliferation was measured via the modified MTT assay. "P<0.05, as indicated. Data are presented as the mean \pm standard deviation of three independent experiments. CDDP, cisplatin.
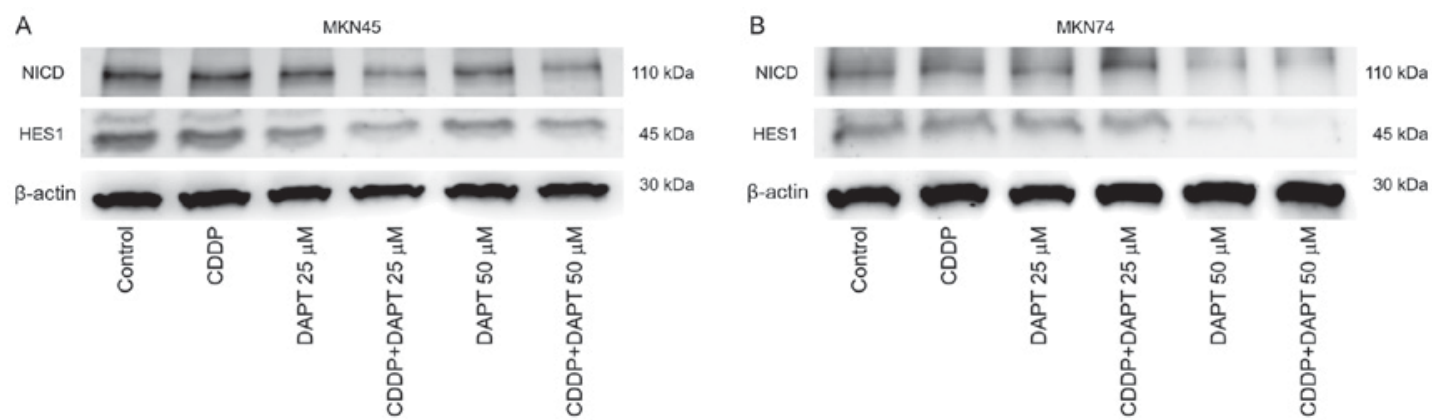

Figure 3. Expression of NICD and the downstream protein HES1 in (A) MKN45 and (B) MKN74 cells. Cells were treated with CDDP (0.5 $\mu \mathrm{g} / \mathrm{ml})$ and/or DAPT $(25$ or $50 \mu \mathrm{M}$ ) for $72 \mathrm{~h}$. Then, cells were lysed and analyzed via immunoblot analysis using antibodies targeting NICD and HES1. Antibodies against $\beta$-actin were used to verify equal loading of cellular proteins. Representative blots of $>3$ independent experiments are presented. NICD, intracellular domain of the Notch receptor; HES1, Hes family basic helix-loop-helix transcription factor 1; DAPT, dipeptide $\gamma$-secretase inhibitor; CDDP, cisplatin.
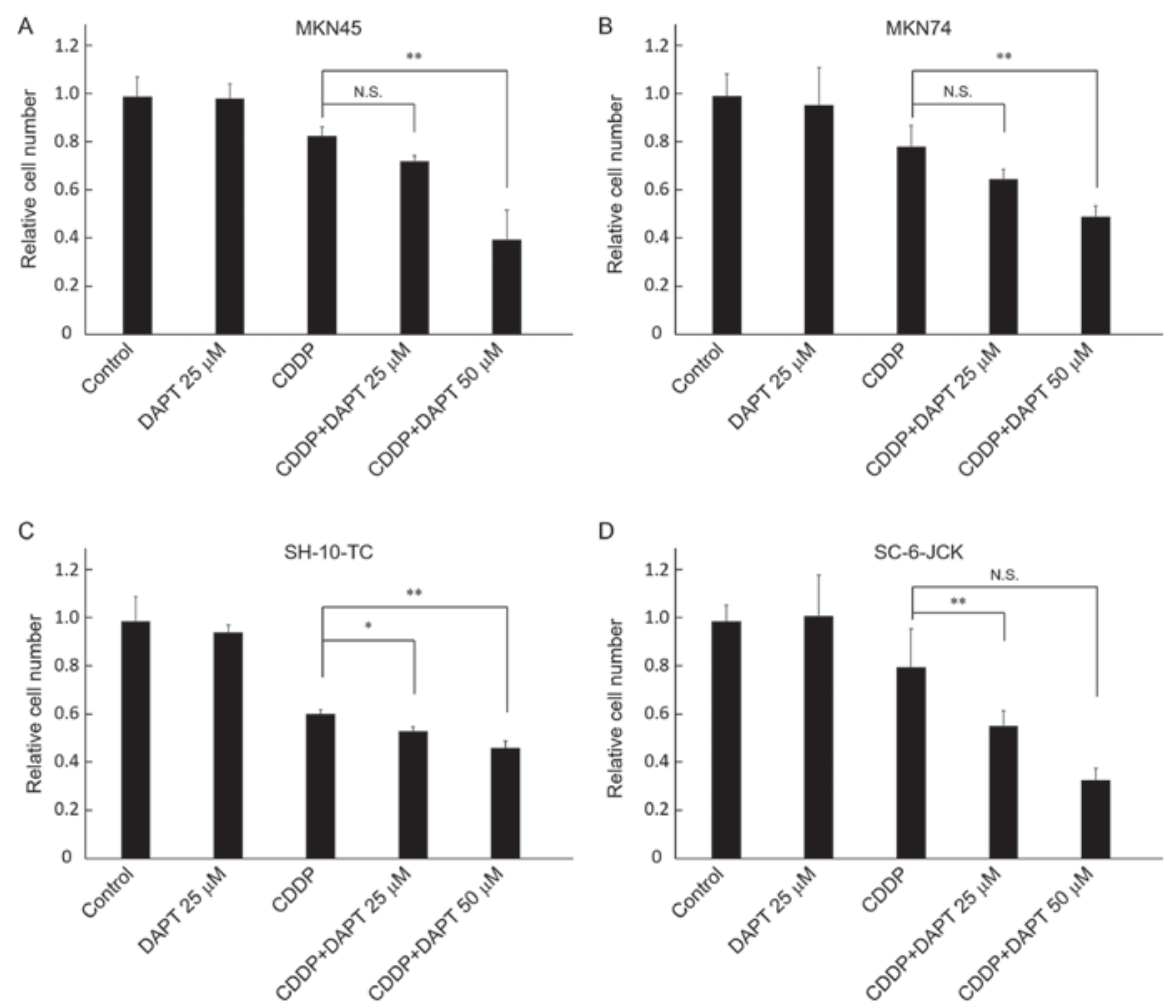

Figure 4. Proliferation in the four gastric cancer cell lines, (A) MKN45, (B) MKN74, (C) SC-10-TC and (D) SH-6-JCK upon combined treatment with DAPT and CDDP. Cells were treated with CDDP $(0.5 \mu \mathrm{g} / \mathrm{ml})$ and/or DAPT $(25$ or $50 \mu \mathrm{M})$ for $72 \mathrm{~h}$. Then, cells were lysed and analyzed via MTT assay. "P<0.05 and ${ }^{* *} \mathrm{P}<0.01$, as indicated. Data are presented as the mean \pm standard error of the mean of $>3$ independent experiments performed in triplicate. N.S., not significant; DAPT, dipeptide $\gamma$-secretase inhibitor; CDDP, cisplatin. 

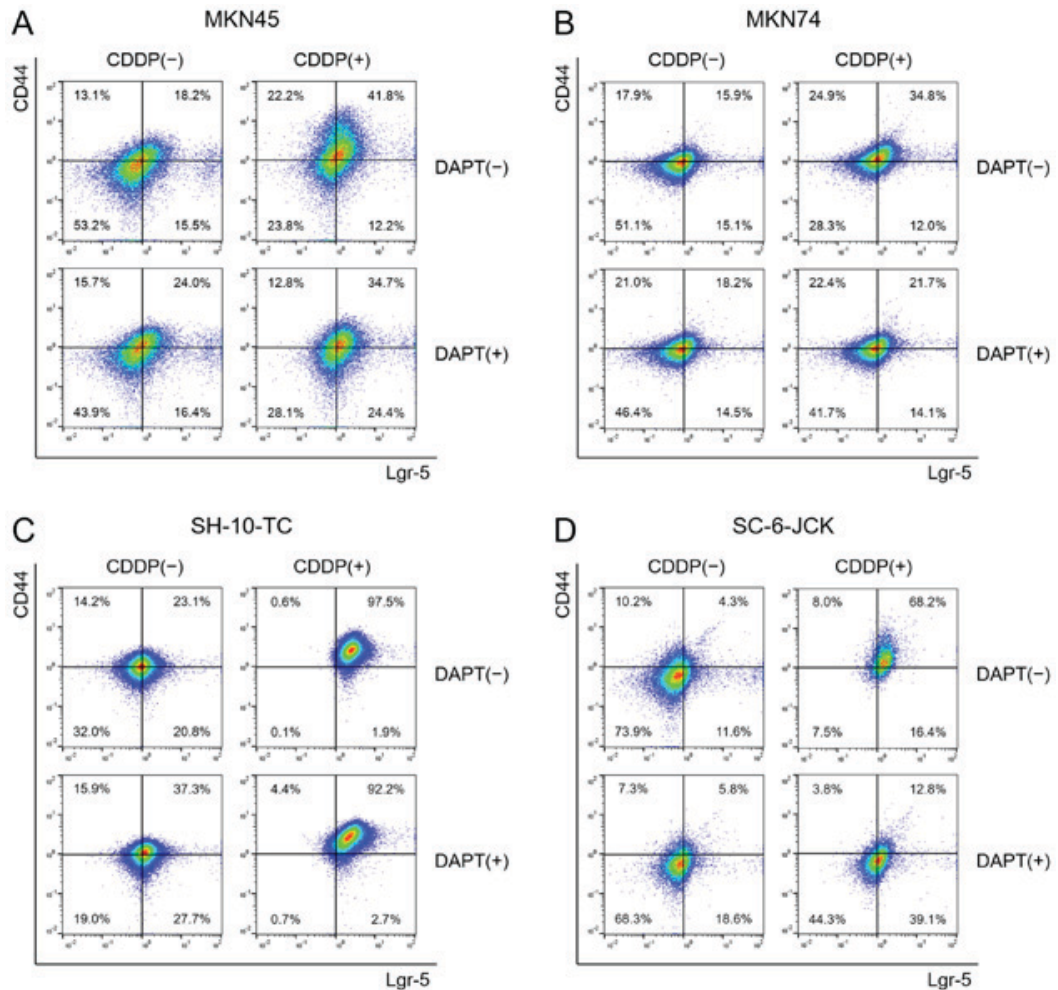

Figure 5. Expression of CD44 and Lgr-5 in (A) MKN45, (B) MKN74, (C) SH-10-TC and (D) SC-6-JCK cells upon combined treatment with DAPT and CDDP. Cells were cultured with or without CDDP and DAPT for $72 \mathrm{~h}$. Then, cells were analyzed via flow cytometry using anti-CD44 and anti-Lgr-5 antibodies. Representative plots from $>3$ independent experiments are presented. CD44, cluster of differentiation 44; Lgr-5, leucine-rich repeat-containing G-protein coupled receptor 5; DAPT, dipeptide $\gamma$-secretase inhibitor; CDDP, cisplatin.

Our results also revealed that the $\mathrm{Lgr}-5^{\text {high }}$ fraction was higher in the cisplatin treatment group than in the control group. However, the results of our study also suggested that unlike CD44 expression, $\gamma$-secretase inhibitor treatment did not directly modulate Lgr-5 expression in gastric cancer cells.

Fig. 6 shows results of statistical analysis with respect to percentages of CD44 $4^{\text {high }}$ cells and $\mathrm{Lgr} 5^{\text {high }}$ cells. In MKN45, MKN74, SH-10-TC, and SC-6-JCK cell lines, treatment with cisplatin alone significantly increased the proportions of both $\mathrm{CD} 44^{\text {high }}$ cells and $\mathrm{Lgr}^{\text {high }}$ cells. The proportions of CD $44^{\text {high }}$ cells and $\mathrm{Lgr}-5^{\text {high }}$ cells observed after combination treatment with DAPT and cisplatin were significantly lower than those observed after treatment with cisplatin alone in MKN45, MKN74, and SC-6-JCK cell lines; however, this significant difference was not observed in CD44 ${ }^{\text {high }}$ MKN74 cells.

\section{Discussion}

In the current study, we demonstrated that DAPT enhanced the cytotoxic effects of cisplatin in gastric cancer cells. Notably, although treatment with cisplatin alone increased the proportion of cells positive for cancer stem cell markers, combination treatment with DAPT and cisplatin reduced the proportion of such cells. The above results indicated that Notch signaling inhibition could induce enhanced chemotherapeutic effects when administered in combination with anti-tumor drugs by reducing the proportion of chemoresistant cancer stem cells relative to other tumor cells.

The therapeutic potential of $\gamma$-secretase inhibitors combined with 5-fluorouracil (FU) has been previously investigated (9).
Lee et al (9) revealed that cbz-IL-CHO, a $\gamma$-secretase inhibitor I, reduced the proliferation of gastric cancer cells in vitro and in vivo when administered in combination with 5-FU. They demonstrated that $\gamma$-secretase inhibitor I mediated Akt signaling inhibition and subsequent apoptosis, G2/M arrest, and cell death in gastric cancer cells. Moreover, $\gamma$-secretase inhibitor I in combination with 5-FU promoted apoptosis of gastric cancer cells via activation of both the extrinsic and intrinsic apoptotic pathways. In the present study, we demonstrated that treatment of gastric cancer cell lines with DAPT, $\gamma$-secretase inhibitor IX, and cisplatin in combination was more effective than treatment with DAPT or cisplatin alone.

Cisplatin and 5-FU are two of the major chemotherapeutic agents used for the treatment of gastric cancers. Acquired cisplatin resistance remains a serious concern in the management of gastric cancer patients. Notch signaling has been suggested to be involved in the development of cisplatin resistance $(12,13)$. We speculated that cancer stem cells play critical roles in mediating cisplatin resistance, since they express drug transporters that counteract the cytotoxic effects of chemotherapeutic agents, as described above. Our flow cytometry results showed that the number of gastric cancer cells positive for CD44 and Lgr-5 increased upon treatment with cisplatin alone, whereas combined treatment with DAPT and cisplatin decreased the number of positive cells. The above results indicated that the chemoresistant fraction increased after cisplatin treatment and that DAPT partly altered the chemosensitivity of the cells. Although previous studies have shown the chemosensitivity induced by manipulating the Notch signaling pathway through inhibiting tumor stem cells (14-16), there have been limited 
A

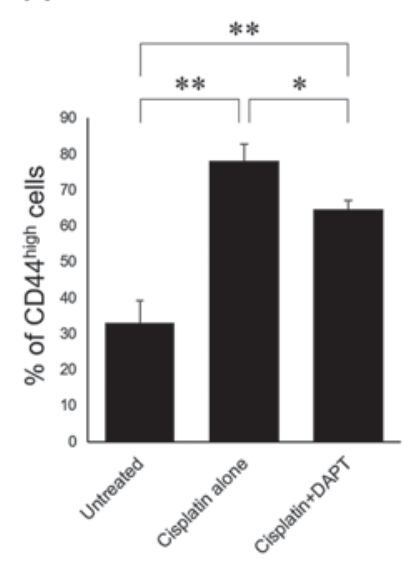

$\mathrm{E}$

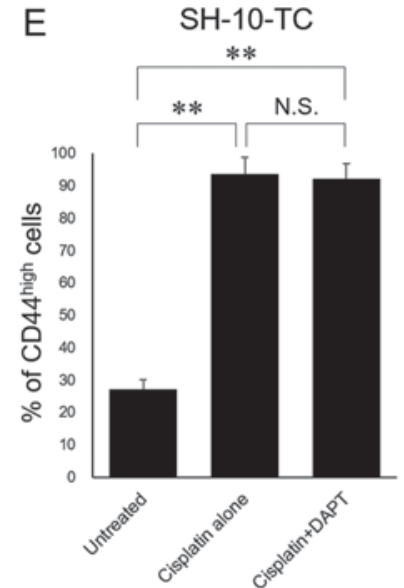

B

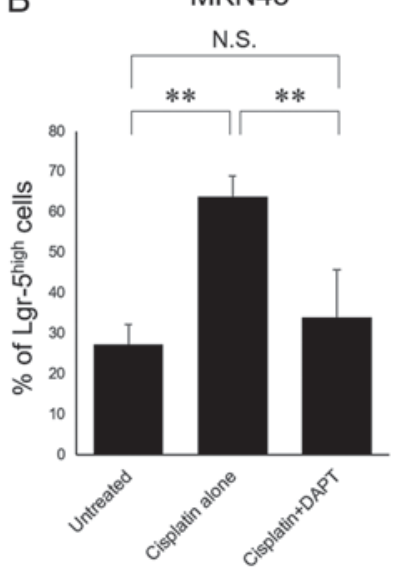

$\mathrm{F}$

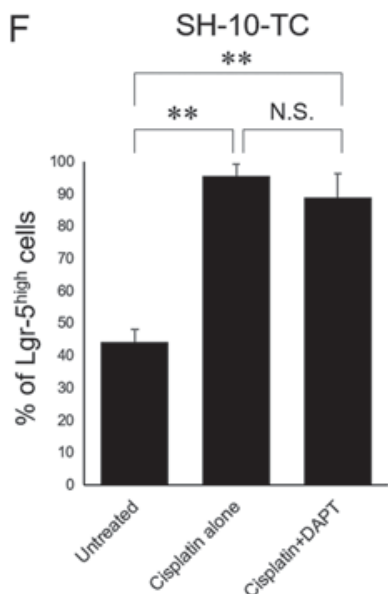

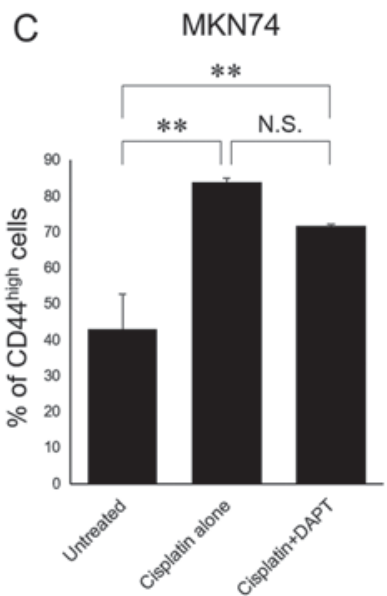
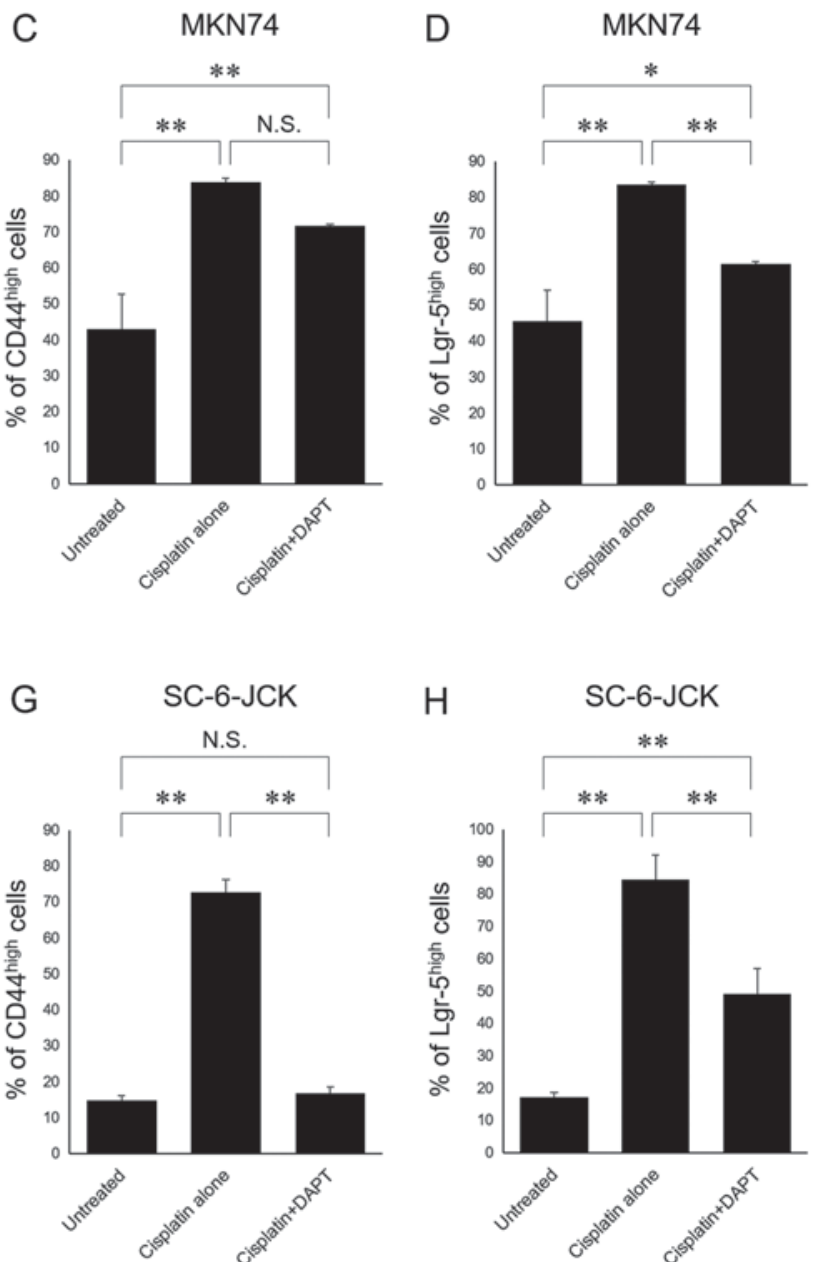

$\mathrm{H}$

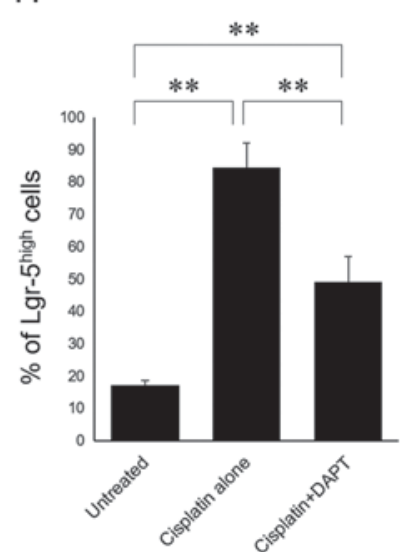

Figure 6. Statistical analysis of CD44 and Lgr-5 expression in (A and B) MKN45, (C and D) MKN74, (E and F) SH-10-TC and (G and H) SC-6-JCK cells. Cells were cultured without cisplatin or DAPT (untreated controls), with cisplatin alone, or with DAPT and cisplatin for $72 \mathrm{~h}$. Then, cells were analyzed via flow cytometry using anti-CD44 and anti-Lgr-5 antibodies. Three samples were used to calculate the mean \pm standard deviation. " $\mathrm{P}<0.05$ and ${ }^{* *} \mathrm{P}<0.01$, as indicated. N.S., not significant; CD44, cluster of differentiation 44; Lgr-5, leucine-rich repeat-containing G-protein coupled receptor 5; DAPT, dipeptide $\gamma$-secretase inhibitor.

reports on gastric cancer cells. Moreover, to our knowledge, this study is the first to investigate the effect of combination treatment with cisplatin and DAPT.

CD44 and Lgr-5 are recognized as surface markers of gastric cancer stem cells (17-23). Xi et al (24) investigated a total of 68 gastric cancer patients and revealed that positive staining for Lgr-5 was significantly associated with weaker response to chemotherapy and shorter survival periods than patients negative for Lgr-5. Li et al (21) revealed that CD44+ cells exhibited cancer stem cell characteristics. These cells showed higher Notch1 expression and were more chemoresistant than CD44- cells. In addition, treatment with DAPT inhibited cancer stem cell properties and suppressed the invasion and proliferation capabilities of CD44+ cells. Furthermore, the present study revealed that DAPT treatment augmented the cytotoxic effects of cisplatin and reduced the CD $44^{\text {high }}$ Lgr- $5^{\text {high }}$ fraction in gastric cancer cell lines.

Du et al (11) investigated the association between Notch signaling and gastric cancer by conducting a meta-analysis based on 15 studies representing a total of 1,547 gastric cancer cases and 450 controls. Expression levels of Notch receptors (Notch1 and Notch2) and their ligands (DLL-4 and HES-1) were found to be significantly higher in gastric cancer tissues than in normal tissues. Notch signaling has been speculated to be involved in carcinogenesis and disease progression in gastric cancers. Moreover, protein levels of Notch1 and Jagged-1 have been established as adverse prognostic factors for gastric cancers $(11,25)$. Thus, direct suppression of the Notch pathway serves as a promising strategy for the treatment of gastric cancers, as well as for enhancing the cytotoxicity of antitumor drugs.

Our study has several limitations. First, we investigated in vitro effects of DAPT in cultured cells. Further comprehensive studies on animals and clinical specimens are required to examine in vivo synergistic antitumor effects of DAPT. Second, although CD44 and Lgr-5 have been widely known and investigated as stem cell markers in gastric cancer cells $(26,27)$, functional assays are needed to investigate how DAPT directly affects stemness. We would like to treat them as the subjects of our next studies.

In conclusion, our findings demonstrated the therapeutic potential of DAPT in the treatment of gastric cancer. Furthermore, combined treatment with DAPT with cisplatin showed enhanced chemotherapeutic effects, particularly in 
reducing the population of $\mathrm{CD} 44^{\text {high }} \mathrm{Lgr}-5^{\text {high }}$ cells, which exhibit cancer stem cell-like properties. We hope the data obtained in this study will serve as useful reference for future research to overcome acquired cisplatin resistance during gastric cancer treatment.

\section{Acknowledgements}

The authors would like to thank Ms. Yuki Osaki (Department of Gastroenterology and Hepatology, Okayama University Graduate School of Medicine, Dentistry and Pharmaceutical Sciences, Okayama, Japan) for their technical assistance during the experiments.

\section{Funding}

The present study was partially supported by Takeda Pharmaceutical Co., Ltd. (grant no. Takeda Research Support 2017).

\section{Availability of data and materials}

The data sets generated and/or analyzed during the current study are available from the corresponding author on reasonable request.

\section{Authors' contributions}

RK, MI, ET, KM, AO, HSa and TN performed the experiments. RK and MI analyzed the data and drafted the manuscript. MI, HSh, SH, DU, KT and HO designed and supervised the study. DU, KT and HO revised the manuscript for important intellectual content. All authors have read and approved the final version to be published.

\section{Ethics approval and consent to participate}

Not applicable.

\section{Patient consent for publication}

Not applicable.

\section{Competing interests}

The authors declare that they have no competing interests.

\section{References}

1. Cancer Information Service, National Cancer Center: Cancer mortality from Vital Statistics in Japan (1958-2016). http://ganjoho.jp/en/professional/statistics/table_download.html.

2. Vinogradov $\mathrm{S}$ and Wei X: Cancer stem cells and drug resistance: The potential of nanomedicine. Nanomedicine (Lond) 7: 597-615, 2012.

3. Abdullah LN and Chow EK: Mechanisms of chemoresistance in cancer stem cells. Clin Transl Med 2: 3, 2013.

4. Colak S and Medema JP: Cancer stem cells-important players in tumor therapy resistance. FEBS J 281: 4779-4791, 2014.

5. Dawood S, Austin L and Cristofanilli M: Cancer stem cells: Implications for cancer therapy. Oncology (Williston Park) 28: 1101-1107, 1110, 2014

6. Artavanis-Tsakonas S, Rand MD and Lake RJ: Notch signaling: Cell fate control and signal integration in development. Science 284: 770-776, 1999.
7. Abel EV, Kim EJ, Wu J, Hynes M, Bednar F, Proctor E, Wang L, Dziubinski ML and Simeone DM: The Notch pathway is important in maintaining the cancer stem cell population in pancreatic cancer. PLoS One 9: e91983, 2014.

8. Huang R, Wang G, Song Y, Tang Q, You Q, Liu Z, Chen Y, Zhang Q, Li J, Li J, Muhammand S and Wang X: Colorectal cancer stem cell and chemoresistant colorectal cancer cell phenotypes and increased sensitivity to Notch pathway inhibitor. Mol Med Rep 12: 2417-2424, 2015.

9. Lee HW, Kim SJ, Choi IJ, Song J and Chun KH: Targeting Notch signaling by $\gamma$-secretase inhibitor I enhances the cytotoxic effect of 5-FU in gastric cancer. Clin Exp Metastasis 32: 593-603, 2015.

10. Katoh M: Dysregulation of stem cell signaling network due to germline mutation, SNP, Helicobacter pylori infection, epigenetic change and genetic alteration in gastric cancer. Cancer Biol Ther 6: 832-839, 2007.

11. Du X, Cheng Z, Wang YH, Guo ZH, Zhang SQ, Hu JK and Zhou ZG: Role of Notch signaling pathway in gastric cancer: A meta-analysis of the literature. World J Gastroenterol 20: 9191-9199, 2014.

12. Zhang ZP, Sun YL, Fu L, Gu F, Zhang L and Hao XS: Correlation of Notch1 expression and activation to cisplatin-sensitivity of head and neck squamous cell carcinoma. Ai Zheng 28: 100-103, 2009.

13. Gu F, Ma Y, Zhang Z, Zhao J, Kobayashi H, Zhang L and Fu L: Expression of Stat 3 and Notch 1 is associated with cisplatin resistance in head and neck squamous cell carcinoma. Oncol Rep 23: 671-676, 2010.

14. Cui D, Dai J, Keller JM, Mizokami A, Xia S and Keller ET: Notch pathway inhibition using PF-03084014, a $\gamma$-secretase inhibitor (GSI), enhances the antitumor effect of docetaxel in prostate cancer. Clin Cancer Res 21: 4619-4629, 2015.

15. Wang Z, Da Silva TG, Jin K, Han X, Ranganathan P, Zhu X, Sanchez-Mejias A, Bai F, Li B, Fei DL, et al: Notch signaling drives stemness and tumorigenicity of esophageal adenocarcinoma. Cancer Res 74: 6364-6374, 2014.

16. Qiu M, Peng Q, Jiang I, Carroll C, Han G, Rymer I, Lippincott J, Zachwieja J, Gajiwala K, Kraynov E, et al: Specific inhibition of Notch1 signaling enhances the antitumor efficacy of chemotherapy in triple negative breast cancer through reduction of cancer stem cells. Cancer Lett 328: 261-270, 2013.

17. Han ME, Jeon TY, Hwang SH, Lee YS, Kim HJ, Shim HE, Yoon S, Baek SY, Kim BS, Kang CD and Oh SO: Cancer spheres from gastric cancer patients provide an ideal model system for cancer stem cell research. Cell Mol Life Sci 68: 3589-3605, 2011.

18. Chen T, Yang K, Yu J, Meng W, Yuan D, Bi F, Liu F, Liu J, Dai B, Chen $\mathrm{X}$, et al: Identification and expansion of cancer stem cells in tumor tissues and peripheral blood derived from gastric adenocarcinoma patients. Cell Res 22: 248-258, 2012.

19. Jiang J, Zhang Y, Chuai S, Wang Z, Zheng D, Xu F, Zhang Y, Li C, Liang Y and Chen Z: Trastuzumab (herceptin) targets gastric cancer stem cells characterized by CD90 phenotype. Oncogene 31: 671-682, 2012.

20. Xu G, Shen J, Ou Yang X, Sasahara M and Su X: Cancer stem cells: The 'heartbeat' of gastric cancer. J Gastroenterol 48: 781-797, 2013.

21. Li LC, Wang DL, Wu YZ, Nian WQ, Wu ZJ, Li Y, Ma HW and Shao JH: Gastric tumor-initiating CD $44^{+}$cells and epithelial-mesenchymal transition are inhibited by $\gamma$-secretase inhibitor DAPT. Oncol Lett 10: 3293-3299, 2015.

22. Wang Z and Liu C: Lgr5-positive cells are cancer-stem-cell-like cells in gastric cancer. Cell Physiol Biochem 36: 2447-2455, 2015.

23. Zhang L, Guo X, Zhang D, Fan Y, Qin L, Dong S and Zhang L: Upregulated miR-132 in $\mathrm{Lgr}^{+}$gastric cancer stem cell-like cells contributes to cisplatin-resistance via SIRT1/CREB/ABCG2 signaling pathway. Mol Carcinog 56: 2022-2034, 2017.

24. Xi HQ, Cui JX, Shen WS, Wu XS, Bian SB, Li JY, Song Z, Wei B and Chen L: Increased expression of Lgr5 is associated with chemotherapy resistance in human gastric cancer. Oncol Rep 32: 181-188, 2014.

25. Chang HH, Lee H, Hu MK, Tsao PN, Juan HF, Huang MC, Shih YY, Wang BJ, Jeng YM, Chang CL, et al: Notch1 expression predicts an unfavorable prognosis and serves as a therapeutic target of patients with neuroblastoma. Clin Cancer Res 16: 4411-4420, 2010.

26. Li XB, Yang G, Zhu L, Tang YL, Zhang C, Ju Z, Yang X and Teng Y: Gastric Lgr5(+) stem cells are the cellular origin of invasive intestinal-type gastric cancer in mice. Cell Res 26: 838-849, 2016.

27. Watanabe T, Okumura T, Hirano K, Yamaguchi T, Sekine S, Nagata $T$ and Tsukada K: Circulating tumor cells expressing cancer stem cell marker CD44 as a diagnostic biomarker in patients with gastric cancer. Oncol Lett 13: 281-288, 2017. 